\title{
An evaluation of wind energy potential in the northern and southern regions of Nigeria on the basis of Weibull and Rayleigh models
}

\author{
Abdullahi Ahmed ${ }^{1}$, Adisa Ademola Bello², Dandakuta Habou ${ }^{2}$ \\ ${ }^{1}$ Department of Mechanical Engineering, Kano University of Science and Technology, Wudil, Nigeria \\ ${ }^{2}$ Department of Mechanical Engineering, Abubakar Tafawa Balewa University, Bauchi, Nigeria
}

Email address:

abdula2k2@yahoo.com(A.Ahmed), biieeyz@yahoo.com(A. A. Bello), dandakuta@yahoo.co.uk (D. Habou)

\section{To cite this article:}

Abdullahi Ahmed, Adisa Ademola Bello, Dandakuta Habou. An Evaluation of Wind Energy Potential in the Northern and Southern Regions of Nigeria on the Basis of Weibull and Rayleigh Models. American Journal of Energy Engineering.

Vol. 1, No. 3, 2013, pp. 37-42. doi: 10.11648/j.ajee.20130103.11

\begin{abstract}
This paper presents an evaluation of wind energy potential in the northern and southern region of Nigeria on the basis of Weibull and Rayleigh models. The aim of this study is to know which of the locations in the regions would have more wind power density where wind energy conversion system (WECS) could be installed for electricity generation in Nigeria with excellent percentage of clean energy. From the analysis of the wind speed data collected from Nigeria meteorological station, Abuja at 10m height from years (1990 - 2006) the locations in northern region of Nigeria that were found quite viable for electricity generation are (Jos, Kano, Sokoto and Maiduguri) while for the southern region of Nigeria are (Lagos and Enugu). These locations were found to have wind power density above $100 \mathrm{~W} / \mathrm{m}^{2}$. The Weibull model was found to be more applicable in estimating the power density because it returns a lower percentage error than the Rayleigh model. Probability density function in the northern region has a peak value of 1.01795 and 0.2937 in Bauchi for both Weibull and Rayleigh respectively while for the southern region the probability density function has a peak value for Weibull as 0.8347 in Calabar and Rayleigh as 0.2341 in Rivers southern region of Nigeria.
\end{abstract}

Keywords: Wind Energy Potential, Nigeria, Generation, Weibull, Rayleigh, Probability Density Function

\section{Introduction}

Wind energy is a free, clean and inexhaustible energy source. It has served mankind for many centuries by propelling ships and driving wind turbines to grind grains and pump water. Wind power and other forms of solar power are being strongly encouraged. Wind power may become a major source of energy in spite of slightly higher costs than other traditional sources of energy generation. Considerable progress is being made in making wind power less expensive, but even without a clear cost advantage, wind power will become important in the world energy sources. Wind energy is the world's fastest growing energy source and it can power industry, businesses and homes with clean, renewable electricity for many years to come. Wind turbines do not consume fuel due to its operation. It does not produce emissions such as carbon dioxide, sulphur dioxide, mercury, particulates or any other type of air pollution [1].
The major problem associated with extracting energy from the wind is due to the physical properties of air. The density of air is small and therefore, equipment designed to extract appreciable amounts of energy from moving air must be capable of intercepting large air areas. Also, the noise generated by wind turbines is considered and the interference with television reception, due to both rotating components and the fixed installation, may affect wind exploiting. Hazard due to failure of the moving components of the wind turbine is considered as another problem [1].

Akpinar [2] presented a work on statistical analysis of wind energy potential on the basis of the Weibull and Raleigh distribution for Agin-Elazig, Turkey. The work studied 5years measured wind speed data based on the Weibull and Rayleigh models. The Weibull distribution provides better power density estimation in all the twelve months than the Rayleigh distribution.

Shata [3], worked on evaluation of wind energy potential and electricity generation on the coast of Mediterranean sea in Egypt. Wind data for 10 coastal meteorological stations 
along the Mediterranean Sea in Egypt was used in the analysis. Results shows that wind energy potential along the coast of Mediterranean sea in north Egypt is quite promising.

Celik [6], presented a work on statistical analysis of wind power density based on the Weibull and Rayleigh models at the southern region of Turkey. In his study one year monthly measured wind speed data was used, in the analysis Weibull model returns smaller error values in calculating the power density when compared to the Rayleigh model.

Ojosu [8] presented a statistical analysis of wind energy potential for power generation in Nigeria, 15 years (19681983) monthly average wind speed data was used for six sites at four distinctive regions in Nigeria using Weibull distribution. The analysis shows that wind turbine can generate up to $97 \mathrm{MWh} /$ year.

In Nigeria, wind energy is still at an infant stage because is almost an untapped renewable energy source. The participation of government, private and individual to harness the utilization of this clean and inexhaustible energy source is very important for national development. Presently, the existing power plants in Nigeria are; Sayya Gidan-Gada, Sokoto with a capacity of $5 \mathrm{~kW} / \mathrm{h}$, Dan-Jawa, Sokoto with a capacity of $0.75 \mathrm{~kW} / \mathrm{h}$ and Energy research, Benin with a capacity of $1 \mathrm{~kW} / \mathrm{h}$, based on these capacity, the contribution its quite negligible to the total energy consumption in Nigeria [9].

In this study, wind energy potential for twelve locations in the northern and southern regions of Nigeria were analyzed using wind speed data at $10 \mathrm{~m}$ height collected from Nigerian meteorological station NIMET Abuja for the period of (1990-2006). These locations are characterized by different geographical and climatoligical conditions.

This study provides useful information for developing wind sites and planning economical wind turbines capacity for the electricity production in Nigeria.

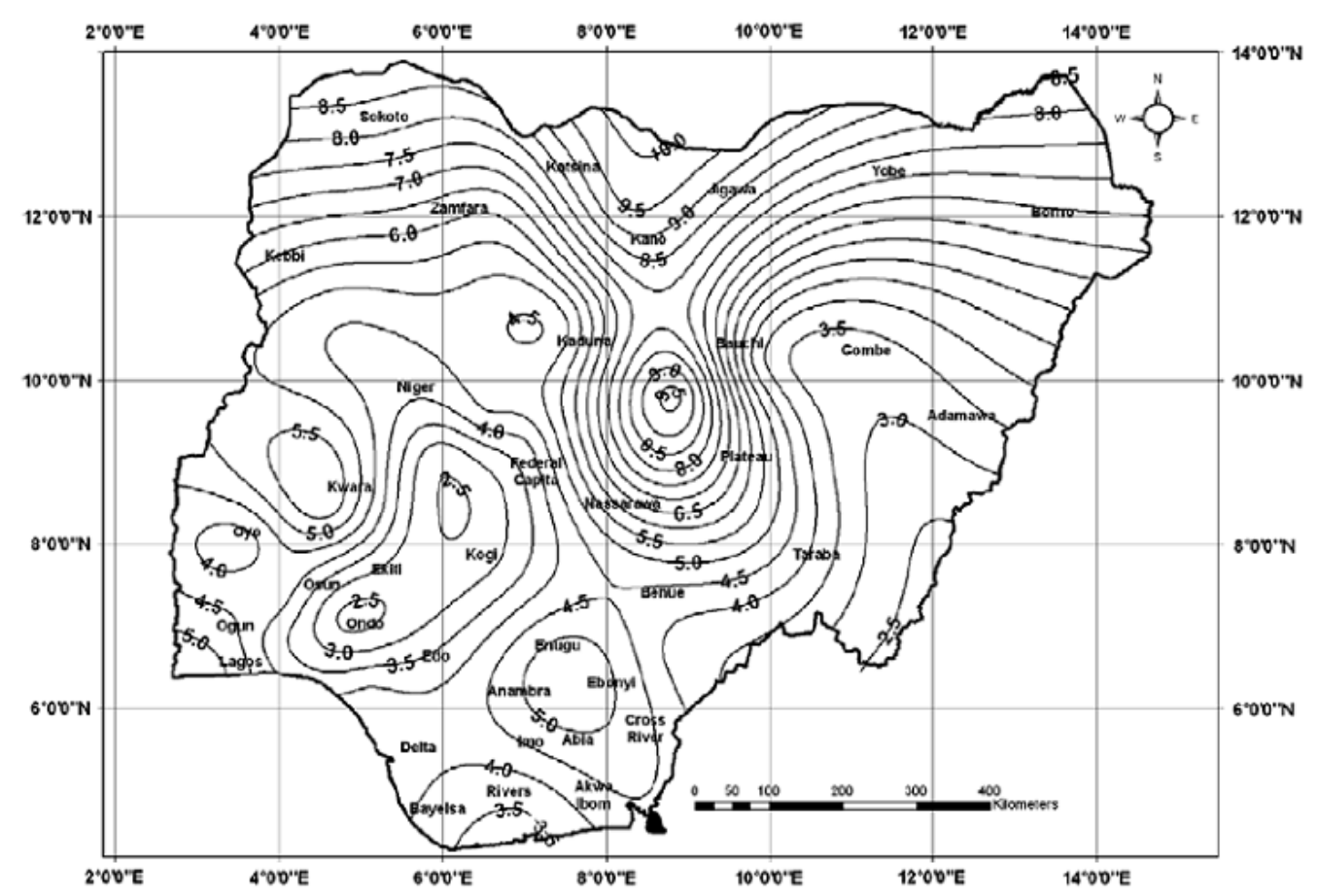

Figure 1: Predicted monthly average wind speeds $(\mathrm{m} / \mathrm{s})$ distribution at $10 \mathrm{~m}$ height in Nigeria (Source: Fadare, 2010).

Table 1: Geographical data for the selected locations

\begin{tabular}{llllll}
\hline LOCATIONS & STATE & LAT (N) & LONG (E) & ALT(M) & ALT (FT) \\
\hline KANO & KANO & $11^{0} 59^{\prime} 47$ & $8^{0} 31^{\prime} 0$ & 476 & 1564 \\
SOKOTO & SOKOTO & $13^{0} 3^{\prime} 5$ & $5^{0} 13^{\prime} 45$ & 272 & 895 \\
BAUCHI & BAUCHI & $10^{0} 18^{\prime} 57$ & $9^{0} 50^{\prime} 39$ & 615 & 2020 \\
MAIDUGURI & BORNO & $1^{0} 50^{\prime} 47$ & $13^{0} 9^{\prime} 37$ & 299 & 984 \\
ABUJA & ABUJA & $9^{0} 15^{\prime} 0$ & $6^{0} 55^{\prime} 60^{\prime}$ & 246 & 810 \\
JOS & PLATEAU & $9^{0} 55^{\prime} 0$ & $8^{0} 54^{\prime}$ & 1217 & 3996 \\
ABEOKUTA & OGUN & $7^{0} 9^{\prime} 0$ & $3^{0} 21^{\prime} 0$ & 66 & 219 \\
LAGOS & LAGOS & $6^{0} 27^{\prime} 11$ & $3^{0} 23^{\prime} 45$ & 34 & 114 \\
ENUGU & ENUGU & $6^{0} 26^{\prime} 25$ & $7^{0} 29^{\prime} 39$ & 247 & 813 \\
OWERRI & IMO & $5^{0} 28^{\prime} 60$ & $7^{0} 1^{\prime} 60$ & 158 & 521 \\
CALABAR & CROSSRIVER & $4^{0} 34^{\prime} 27$ & $6^{0} 58^{\prime} 33$ & 380 & 1249 \\
PORTHARCOURT & RIVERS & $4^{0} 47^{\prime} 34$ & $6^{0} 59^{\prime} 50$ & 465 & 1528 \\
\hline
\end{tabular}




\section{Wind Speed Data and Sites Descriptions}

The present study is based on a data source measured at $10 \mathrm{~m}$ height above ground level for twelve different locations in the northern and southern regions of Nigeria.

The wind speed data were collected during the period $(1990-2006)$ at $10 \mathrm{~m}$ height using a cup anemometer at the meteorological station. Fig. 1 shows the locations and distribution of the sites and table 1 shows the geographical features of these locations. These locations were selected for the analysis based on different geographical features.

\section{Wind Speed Frequency Distribution}

The knowledge of wind speed frequency distribution is very important factor to evaluate the wind potential in an area. If the wind speed in the location is known, then the power potential to the site can easily be obtained. Wind data obtained with various observation methods has a wide range therefore in wind energy analysis, it is necessary to have few parameters that can explain the behaviour of a wide range of wind speed data. The simplest and most practical method for the procedure is to use a distribution function. There are several density functions which can be used to describe the wind speed frequency, the common two are the Weibull and Rayleigh models [4].

The Weibull distribution function which is a two parameter distribution can be expressed as;

$$
\begin{aligned}
& f_{w}(v)=\left(\frac{k}{c}\right)\left(\frac{v}{c}\right)^{k-1} \exp \left[-\left(\frac{v}{c}\right)^{k}\right] \\
& \text { where } f_{w}=\text { Weibull probability density function } \\
& k=\text { shape factor } \\
& c=\text { scale factor }
\end{aligned}
$$

The corresponding cumulative probability function of the Weibull distribution is;

$$
\begin{aligned}
& F_{w}(v)=1-\exp (v / c)^{k} \\
& F_{W}=\text { Weibull cumulative distribution function }
\end{aligned}
$$

The Rayleigh distribution function is a special case of the Weibull distribution in which the shape factor is 2.0. Probability density and cumulative function of Rayleigh distribution are calculated as;

$$
f_{R}(v)=\frac{\pi}{2} \frac{v}{v_{m}^{2}} \exp \left[-\left(\frac{\pi}{4}\right)\left(\frac{v}{v_{m}^{2}}\right)^{k}\right]
$$

$$
\begin{aligned}
& F_{R}(v)=1-\exp \left[-\left(\frac{\pi}{4}\right)\left(\frac{v}{v_{m}}\right)^{2}\right] \\
& \text { where } f_{R}(v)=\text { Rayleigh probability density function } \\
& F_{R}(v)=\text { Rayleigh cummulative distribution fuction }
\end{aligned}
$$

\subsection{Wind Power Density}

The power density evaluation is a fundamental importance in the assessment of wind energy in a given area. The wind power density depends on the air density, the cube of the wind speed and the wind speed distribution. Therefore, this parameter is generally considered a better indicator of wind resource than the wind speed. It can be estimated by using the equation;

$$
p(V)=\frac{1}{3} \rho A V^{3}
$$

Where $\mathrm{P}=$ Power in watts (W)

$A=$ Area perpendicular to wind speed vector in $\left(\mathrm{m}^{2}\right)$

$\mathrm{V}=$ Wind speed in $(\mathrm{m} / \mathrm{s})$

$\rho=$ Average density of air in $\left(\mathrm{kg} / \mathrm{m}^{3}\right)$

$$
P_{W}=\frac{1}{2} \rho c^{3} \Gamma\left[1+\frac{3}{k}\right]
$$

Where $\mathrm{P}_{\mathrm{W}}=$ Weibull Power

$c=$ scale factor $(\mathrm{m} / \mathrm{s})$

$k=$ shape factor (dimensionless)

$\Gamma=$ Gammafunction

$$
P_{R}=\frac{3}{\pi} \rho v_{m}^{3}
$$

Where $\mathrm{P}_{\mathrm{R}}=$ Rayleigh Power

$v_{\mathrm{m}}^{3}=$ mean speed

The yearly average error in calculating power densities using both Weibull and Rayleigh functions is obtained by using equation below;

$$
\text { Error }(\%)=\frac{1}{12} \sum_{i=1}^{12}\left(\frac{P_{W, R}-P_{m, R}}{P_{m, R}}\right)
$$

\section{Results and Discussion}

From the results obtained, table 2 presents yearly average monthly variation of Weibull parameters and wind speed for the northern and southern regions of Nigeria. The Weibull shape factor $(k)$ for northern region of Nigeria varies between $4.13-7.47$, the scale factor (c) varies between $2.58-10.76 \mathrm{~m} / \mathrm{s}$ and wind speed varies between $2.36-10.12 \mathrm{~m} / \mathrm{s}$, while for the southern region of Nigeria Weibull shape $(k)$ varies between $3.51-10.07$, the scale factor $(c)$ varies between $3.35-5.91$ and the wind speed varies from $3.02-5.47 \mathrm{~m} / \mathrm{s}$.

It can be seen from table 3 that the favourable locations for wind power generation in northern region of Nigeria are; Maiduguri, Sokoto, Kano and Jos with values for Weibull 
and Rayleigh varying between $162.51-924.45 \mathrm{~W} / \mathrm{m}^{2}$ and $202.67-1256.11 \mathrm{~W} / \mathrm{m}^{2}$ respectively, while for southern region of Nigeria the favourable locations are; Enugu and Lagos with values varying between $152.35-197.02 \mathrm{~W} / \mathrm{m}^{2}$ and $172.21-188.73 \mathrm{~W} / \mathrm{m}^{2}$.

Table 4, presents the percentage error for Weibull and Rayleigh models, from the results shown, it can be seen that Rayleigh models returns high percentage error in all the locations considered in this research.

Comparison of probability density function according to observed data with Weibull and Rayleigh models for the investigated sites is illustrated in the figures 2 - 5 below. It is seen from figure 2 and 3 that Bauchi shows peak value of probability density function as 1.01795 and 0.2937 for Weibull and Rayleigh, while figure 4 shows that Calabar has a peak value for Weibull probability density function as 0.8347 and Rivers has the peak value for Rayleigh probability density function as 0.2341 .

Table 2: Weibull distribution parameters at $10 \mathrm{~m}$ height.

\begin{tabular}{llll}
\hline Locations & $\boldsymbol{k}$ & $\boldsymbol{c}(\boldsymbol{m} / \mathbf{s})$ & $\boldsymbol{v}(\boldsymbol{m} / \mathbf{s})$ \\
\hline Northern region & & & \\
Kano & 6.71 & 9.35 & 8.74 \\
Sokoto & 6.02 & 7.69 & 7.14 \\
Bauchi & 4.71 & 2.58 & 2.36 \\
Maiduguri & 5.47 & 5.90 & 5.45 \\
Abuja & 4.13 & 4.12 & 3.74 \\
Jos & 7.47 & 10.76 & 10.12 \\
Southern region & & & \\
Abeokuta & 3.51 & 3.35 & 3.02 \\
Lagos & 3.79 & 5.91 & 5.33 \\
Enugu & 8.92 & 5.80 & 5.47 \\
Owerri & 5.62 & 3.55 & 3.27 \\
Calabar & 10.07 & 4.60 & 4.42 \\
Rivers & 5.03 & 3.54 & 3.25 \\
\hline
\end{tabular}

Table 3: Weibull and Rayleigh Power density

\begin{tabular}{llll}
\hline Locations & $\mathbf{P}_{\mathbf{W}}\left(\mathbf{W} / \mathbf{m}^{\mathbf{2}}\right)$ & $\mathbf{P}_{\mathbf{R}}\left(\mathbf{W} / \mathbf{m}^{\mathbf{2}}\right)$ & $\mathbf{P}_{\mathbf{m R}}\left(\mathbf{W} / \mathbf{m}^{\mathbf{2}}\right)$ \\
\hline Northern region & & & \\
Kano & 618.45 & 818.10 & 538.89 \\
Sokoto & 360.22 & 460.62 & 274.12 \\
Bauchi & 14.43 & 17.29 & 11.02 \\
Maiduguri & 162.51 & 202.67 & 120.49 \\
Abuja & 55.53 & 62.44 & 41.39 \\
Jos & 924.45 & 1256.11 & 713.95 \\
Southern region & & & \\
Abeokuta & 30.89 & 33.10 & 22.98 \\
Lagos & 172.21 & 188.73 & 119.74 \\
Enugu & 152.35 & 197.02 & 106.03 \\
Owerri & 34.74 & 41.78 & 26.92 \\
Calabar & 68.97 & 102.56 & 56.36 \\
Rivers & 35.08 & 41.85 & 26.59 \\
\hline
\end{tabular}

Table 4: Weibull and Rayleigh \% Error

\begin{tabular}{lll}
\hline Locations & \% Error (Weibull) & $\begin{array}{l}\text { \% Error } \\
\text { (Rayleigh) }\end{array}$ \\
\hline Northern region & & \\
Kano & 23.33 & 61.29 \\
Sokoto & 30.95 & 65.18 \\
Bauchi & 28.04 & 50.74 \\
Maiduguri & 36.23 & 68.11 \\
Abuja & 33.48 & 49.84 \\
Jos & 29.28 & 42.87 \\
Southern region & & \\
Abeokuta & 31.25 & 42.87 \\
Lagos & 40.99 & 58.13 \\
Enugu & 42.64 & 81.31 \\
Owerri & 30.77 & 61.46 \\
Calabar & 22.74 & 82.81 \\
Rivers & 32.67 & 58.38 \\
\hline
\end{tabular}

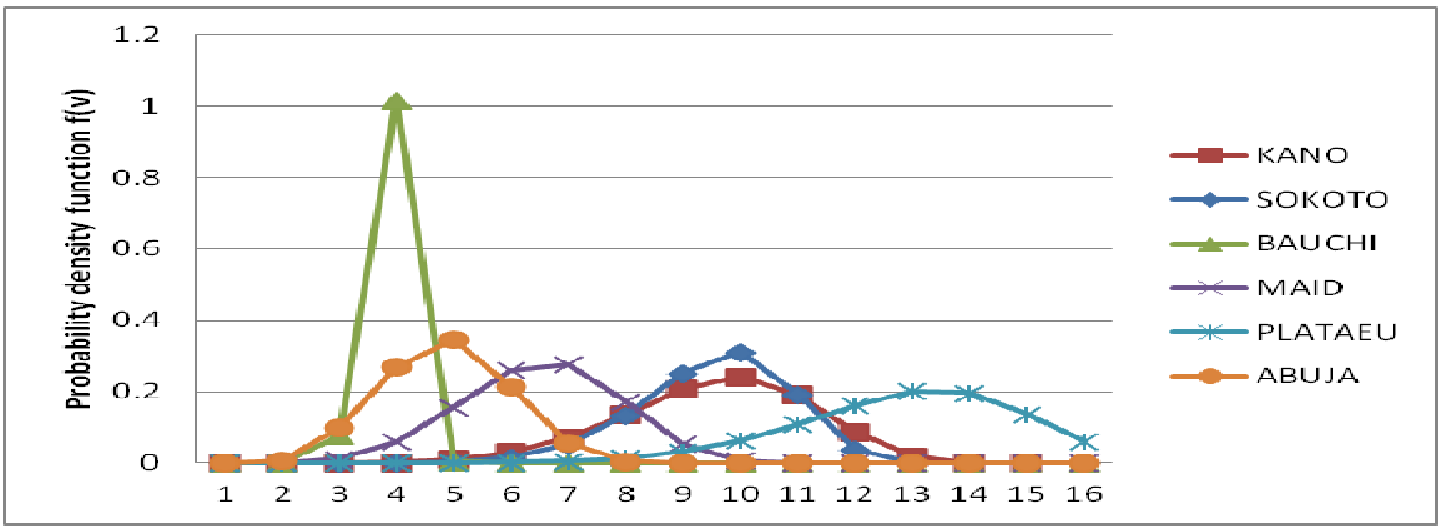

Wind speed $(\mathrm{m} / \mathrm{s})$

Fig 2: Comparison of Weibull probability density functions for northern region. 


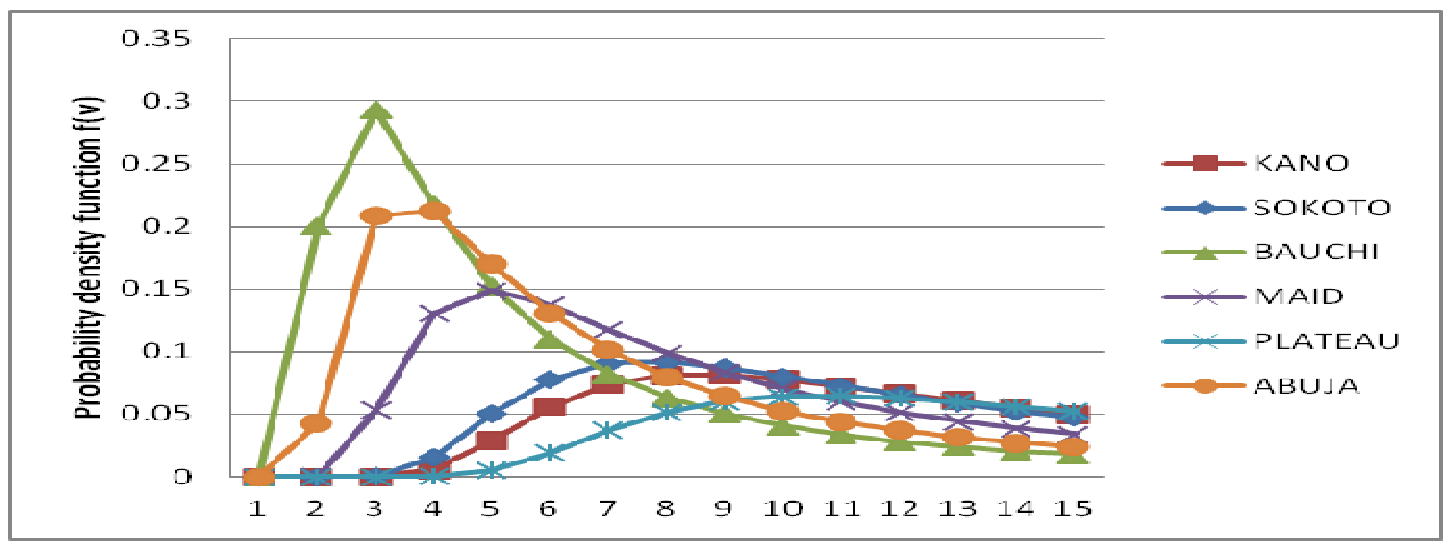

Wind speed $(\mathrm{m} / \mathrm{s})$

Fig 3: Comparison of Rayleigh probability density functions for northern region.

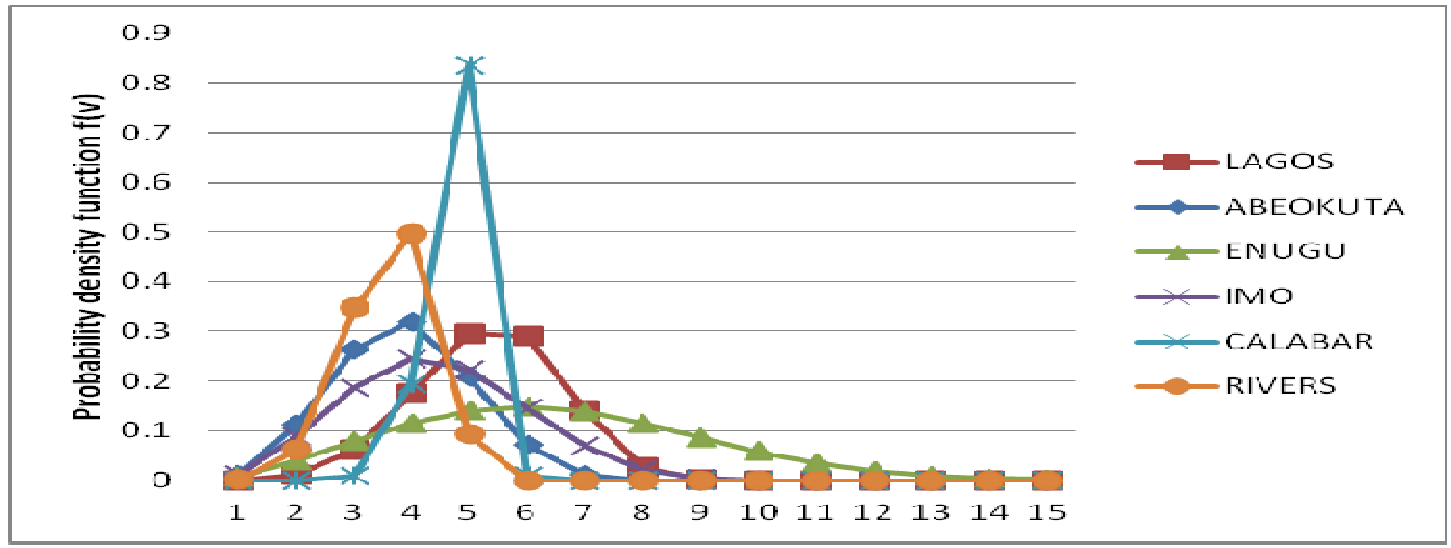

Wind speed $(\mathrm{m} / \mathrm{s})$

Fig 4: Comparison of Weibull probability density functions for southern region.

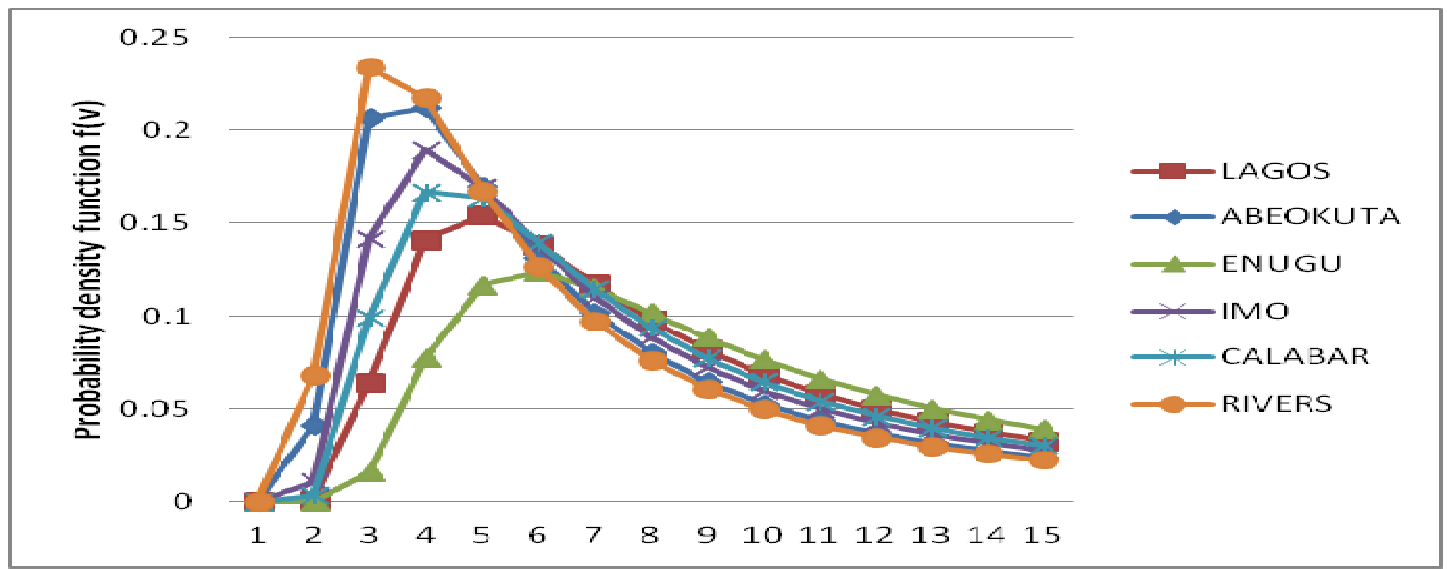

Wind speed $(\mathrm{m} / \mathrm{s})$

Fig 5: Comparison of Rayleigh probability density functions for southern region.

\section{Conclusion}

In this study, the monthly and yearly wind speed distribution and wind power density during the period (1990-2006) in the northern and southern region of Nigeria were evaluated. The wind speed frequency distribution of the locations was found by using Weibull and Rayleigh distribution functions. It can be concluded as follows;

(1). In the northern region, the highest average monthly wind speed occurred in Jos and was determined as $11.74 \mathrm{~m} / \mathrm{s}$ in February while the lowest wind speed occurred in Bauchi with value of $1.47 \mathrm{~m} / \mathrm{s}$ in December. The yearly 
average annual wind speeds for these locations are shown in table 2.

(2). In the southern region, the highest average monthly wind speed occurred in Enugu and was deter- mined as $6.47 \mathrm{~m} / \mathrm{s}$ in April while the lowest wind speed occurred in Rivers with value of $2.5 \mathrm{~m} / \mathrm{s}$ in November. The yearly average annual wind speeds for these locations are shown in table 2 .

(3). The yearly average values for Weibull parameters $(k$ and $c$ ) in the northern region varies between $4.71-7.47$ and $2.58-10.76 \mathrm{~m} / \mathrm{s}$ respectively while for the southern region it varies between $3.51-10.07$ and $3.35-5.91 \mathrm{~m} / \mathrm{s}$ respectively.

(4). In the northern region, the highest average monthly wind power occurred in Jos and was determined as $1469.81 \mathrm{~W} / \mathrm{m}^{2}$ for Weibull and $1892.64 \mathrm{~W} / \mathrm{m}^{2}$ for Rayleigh in February while the lowest average monthly wind power occurred in Bauchi and was determined as $3.87 \mathrm{~W} / \mathrm{m}^{2}$ for Weibull and $3.72 \mathrm{~W} / \mathrm{m}^{2}$ for Rayleigh in December. The yearly average annual wind powers for these locations are presented in table 3 .

(5). In the southern region, the highest average monthly average wind power occurred in Lagos and was determined as $301.46 \mathrm{~W} / \mathrm{m}^{2}$ for Weibull and $312.48 \mathrm{~W} / \mathrm{m}^{2}$ for Rayleigh in the month of August while the lowest average monthly wind power occurred in Rivers and was determined as $15.77 \mathrm{~W} / \mathrm{m}^{2}$ for Weibull and $18.53 \mathrm{~W} / \mathrm{m}^{2}$ for Rayleigh in November.

(6). In calculating error in power density in both regions, the Weibull model returns smaller errors in calculating the power density compared to the Rayleigh model.

Finally, the Weibull distribution provides better power density estimation in both regions than the Rayleigh model since it returns lower error in power estimation.

\section{References}

[1] Alsaad MK. Wind energy potential in selected areas in Jordan. Energy Conversion and Management 2013; 65:704 -708 .
[2] Akinpar EK, Akinpar S. Statistical analysis of wind energy potential on the basis of the Weibull and Rayleigh distribution for Agin-Elazig, Turkey. Power and Energy 2004; $218: 557-565$.

[3] Ahmed Shata AS, Hanitsch R. Evaluation of wind energy potential and electricity generation on the coast of Mediterranean Sea Egypt. Renewable Energy 2006; 31:1183-202.

[4] Ahmed Shata AS, Hanistsch R. The potential of electricity generation on the east coast of Red Sea in Egypt. Renewable Energy 2006; 31: $1597-625$.

[5] Celik AN. On the distributional parameters used in assessment of the suitability of wind speed probability density functions. Energy Conversion and Management 2004; 45: 1735 - 47 .

[6] Celik AN: A statistical analysis of wind power density based on the Weibull and Rayleigh Models at the southern region of Turkey. Renewable Energy 2004; 29:593 - 604.

[7] Celik AN. Assessing the suitability of wind speed probability distribution functions based on the wind power density. Renewable Energy2003; 28:1563 -1574.

[8] Ojosu JO, Salawu RI. A statistical analysis of wind energy potential for power generation in Nigeria. Journal of Solar Energy 1989; 8: 273 - 288.

[9] Amina I, Nafi'u T, Bilyaminu A. Wind power: An untapped renewable energy resource in Nigeria. International Journal of Scientific \& Engineering Research 2012; 3: ISSN 2229 5518.

[10] Oztopal A, Sahin AD, Akgun N, Sen Z: On the regional wind energy potential of Turkey. Energy 2000; 25: $189-$ 200.

[11] Sambo AS.T he renewable energy for rural development. The Nigerian perspective "ISESCO" Science and Technology vision May, 2005; 1:16 -18.

[12] Salem AL. Characteristics of surface wind speed and direction over Egypt .Solar Energy for sustainable development 2004; 4: 491 - 499.

[13] Ulgen K, Hepbasli A. Determination of Weibull parameter for wind energy analysis of Izmir, Turkey. International Journal of Energy Research 2002; 26:495 - 506. 